Hydrol. Earth Syst. Sci., 17, 2657-2668, 2013

www.hydrol-earth-syst-sci.net/17/2657/2013/

doi:10.5194/hess-17-2657-2013

(C) Author(s) 2013. CC Attribution 3.0 License.

\title{
Spatial distribution of stable water isotopes in alpine snow cover
}

\author{
N. Dietermann ${ }^{1, \dagger}$ and M. Weiler ${ }^{1}$ \\ ${ }^{1}$ Institute of Hydrology, University Freiburg, Freiburg, Germany \\ ${ }^{\dagger}$ Died in an accident on 20 April 2012 in the mountains of Kyrgyzstan when sampling snow isotopes for his PhD. \\ Correspondence to: M. Weiler (markus.weiler@hydrology.uni-freiburg.de)
}

Received: 29 January 2013 - Published in Hydrol. Earth Syst. Sci. Discuss.: 1 March 2013

Revised: 2 June 2013 - Accepted: 15 June 2013 - Published: 11 July 2013

\begin{abstract}
The aim of this study was to analyse and predict the mean stable water isotopic composition of the snow cover at specific geographic locations and altitudes. In addition, the dependence of the isotopic composition of the entire snow cover on altitude was analysed. Snow in four Swiss catchments was sampled at the end of the accumulation period in April 2010 and a second time during snowmelt in May 2010 and analysed for stable isotope composition of ${ }^{2} \mathrm{H}$ and ${ }^{18} \mathrm{O}$. The sampling was conducted at both south-facing and north-facing slopes at elevation differences of $100 \mathrm{~m}$, for a total altitude difference of approximately $1000 \mathrm{~m}$. The observed variability of isotopic composition of the snow cover was analysed with stepwise multiple linear regression models. The analysis indicated that there is only a limited altitude effect on the isotopic composition when considering all samples. This is due to the high variability of the isotopic composition of the precipitation during the winter months and, in particular in the case of south-facing slopes, an enrichment of heavy isotopes due to intermittent melting processes. This enrichment effect could clearly be observed in the samples which were taken later in the year. A small altitudinal gradient of the isotopic composition could only be observed at some north-facing slopes. However, the dependence of snow depth and the day of the year were significant predictor variables in all models. This study indicates the necessity to further study the variability of water isotopes in the snow cover to increase prediction for isotopic composition of snowmelt and hence increase model performance of residence time models for alpine areas in order to better understand the accumulation processes and the sources of water in the snow cover of high mountains.
\end{abstract}

\section{Introduction}

For more than $40 \mathrm{yr}$ the stable water isotopes ${ }^{18} \mathrm{O}$ and ${ }^{2} \mathrm{H}$ have been used to determine hydrological pathways and processes in catchment hydrology (McDonnell, 2003). Due to their conservative nature in the water cycle, the relative simple sampling and nowadays cheaper and faster measurement technique, they are a commonly used tracer to determine the mean residence time of water in a catchment (Vitvar et al., 2007). One of the first studies that used stable isotopes of water to determine snowmelt runoff was from Dincer et al. (1970) and was followed by several of other studies (e.g. Rodhe, 1981; Wels et al., 1991; Unnikrishna et al., 2002; Laudon et al., 2002). But modelling the isotopic composition of snowmelt water and the resulting isotopic composition of surface and groundwater is complicated due to different isotope fractionations during formation, accumulation, and ablation of snow and phase changes during snowmelt (Cooper, 1998). Especially isotope fractionation processes during the ablation period are still poorly understood (Unnikrishna et al., 2002). However, a detailed knowledge of the isotopic composition of snow and snowmelt water can help us understand the snowmelt contribution to streamflow and/or the residence time of snowmelt in a catchment (e.g. Shanley et al., 2002; Schelker et al., 2011).

In contrast to liquid precipitation, which undergoes isotopic exchange with atmospheric humidity while falling, snow maintains the isotopic content that was formed while becoming condensation in the clouds (Gat, 1996). The initial isotopic content of snowfall contributes to the integrated snowpack signal, but mass transport through wind drift and avalanches and equilibrium and kinetic fractionation modify snow water isotopic content. During precipitation-free periods the snow is removed layer by layer through sublimation. 
The resulting fractionation is a function of temperature and resultant vapour pressure gradients both within the snowpack and between the snowpack and atmosphere. Unlike the evaporation from the surface of a water body in which the remaining water accumulates steadily in heavy isotopes, one would expect that no isotopic change occurs in the remaining snow cover due to complete sublimation of individual snow crystals. In practice, however, an enrichment of heavy isotopes in the upper snow layers takes place, which happens due to diffusion of water vapour in the pores of the snowpack and also due to partial melting, which causes evaporation and percolation of meltwater in the remaining snow (Gat, 1996; Stichler et al., 2001) as well as kinetic fractionation (Gustafson et al., 2010; Biederman et al., 2012).

The altitude effect of stable water isotopes in precipitation is a well-known effect since the benchmark paper of Dansgaard (1964). Moser and Stichler (1970, 1971) showed that the altitude effect of precipitation by orographic uplift of air masses and the related decrease in the condensation temperature leads to a depletion of heavy isotopes with altitude and can also be observed in fresh snow. In their work they sampled fresh snow in the European Eastern and Western Alps and found an average elevation gradient of about $-3 \%$ o per $100 \mathrm{~m}$ altitude for $\delta^{2} \mathrm{H}$, with variations between -2 to $-10 \%$ per $100 \mathrm{~m}$. Other authors such as Renaud (1969) in Greenland, Gonfiantini (1970) at the Kilimanjaro or Friedman and Smith (1970) in the Sierra Nevada also observed a depletion of heavy isotopes with altitude in fresh snow. These authors examined a depletion of $\delta^{18} \mathrm{O}$ between -0.25 to $-1.25 \%$ o per $100 \mathrm{~m}$. Niewodniczanski et al. (1981) presented a comprehensive study on the altitudinal gradient of the ${ }^{18} \mathrm{O}$ isotope in mountains regions of the world. In the South American Andes, the Central Asian Hindu Kush and Himalaya, as on Mount Kenya and Mount Kilimanjaro in Africa, they took fresh snow samples 5 to $10 \mathrm{~cm}$ below the snow surface. They found an elevation gradient for $\delta^{18} \mathrm{O}$ between -0.6 and $-1.0 \%$ per $100 \mathrm{~m}$. However, the samples were subject to a wide variation with small-scale inverse gradient and were thus only partly attributable to a linear elevation gradient. Niewodniczanski et al. (1981) attributed the variation to the conditions during and after deposition of snow, such as wind drift and fractionation by melting processes, and to topography and climatic conditions of the sampled areas. Moran et al. (2007) collected fresh snow samples in the Canadian Rocky Mountains during two periods of snow accumulation and examined the $\delta^{18} \mathrm{O}$ isotope content. They determined elevation gradients ranging from -0.3 to $+1.8 \%$ o per $100 \mathrm{~m}$ and, as with the Niewodniczanski study, the data collected was subject to a wide variation. It can thus be concluded that an elevation gradient of the isotopic content in fresh snow is only partially observable or very weak. A non-existing elevation gradient can be explained by the fact that air masses in which snow is formed undergo no small-scale orographic uplift and secondly that the source and the trajectory of air masses are essential to the average isotopic content, as well as to the development of a gradient (Moran et al., 2007).

In contrast to the altitudinal gradient in fresh snow samples, the behaviour of the isotopic content of an entire snowpack is even more complex (Moser and Stichler, 1974). Especially in temperate climates, the snowpack is altered by sublimation, evaporation, metamorphism of snow crystals, percolating meltwater, and isotopic enriched precipitation (Judy et al., 1970; Ambach et al., 1972; Arnason et al., 1972; Martinec et al., 1977; Raben and Theakstone, 1994; Aizen et al., 1996; Stichler et al., 2001; Sinclair and Marshall, 2008; Sokratov and Golubev, 2009). These processes can superimpose the isotopic altitude effect of fresh snow and lead to inverse gradients, as observed for example by Moser and Stichler (1970) at the Kitzsteinhorn in Austria. Other authors (Raben and Theakstone, 1994; Gurney and Lawrence, 2004; Königer et al., 2008) observed no significant relation between the isotopic signature of the entire snowpack and elevation. However the total elevation range in these studies was only between 230 and $650 \mathrm{~m}$. Mast et al. (1995) took snow samples of the entire snowpack in an alpine basin in the Rocky Mountains, USA, and could neither detect any relations of the $\delta^{18} \mathrm{O}$ value with altitude nor with snow depth or snow water equivalent. To conclude, the origin of the different air masses is crucial to the isotopic content of the entire snow cover, as the isotopic content of the different snow layers is preserved stratigraphically. Furthermore, the conditions during deposition of snow, and the atmospheric influences after deposition, which depend heavily on the topography of the sampled area, are possible key factors influencing the isotopic content.

To better understand the different factors such as altitude, aspect, slope and other factors influencing the stable isotope composition of the entire snowpack, we sampled stable water isotopes in snow at eight different slopes in Switzerland, covering an altitude difference of approximately $1000 \mathrm{~m}$ per slope. To gain a better understanding of the spatial and temporal variability in potential meltwater isotopic signature during the ablation period, every slope was sampled at the end of the accumulation period and a second time one month later during the ablation period. Therefore the main hypothesis of this study was that a variety of factors in addition to altitude influence the variation of stable water isotopes in the entire snowpack and in the potential meltwater in space and time.

\section{Methods}

\subsection{Sites and sampling design}

Snow was sampled in four Swiss catchments that covered a wide range of climatic influences of the alpine region and altitudinal differences of more than $1000 \mathrm{~m}$, included only a low proportion of glaciated area, and had accessible 


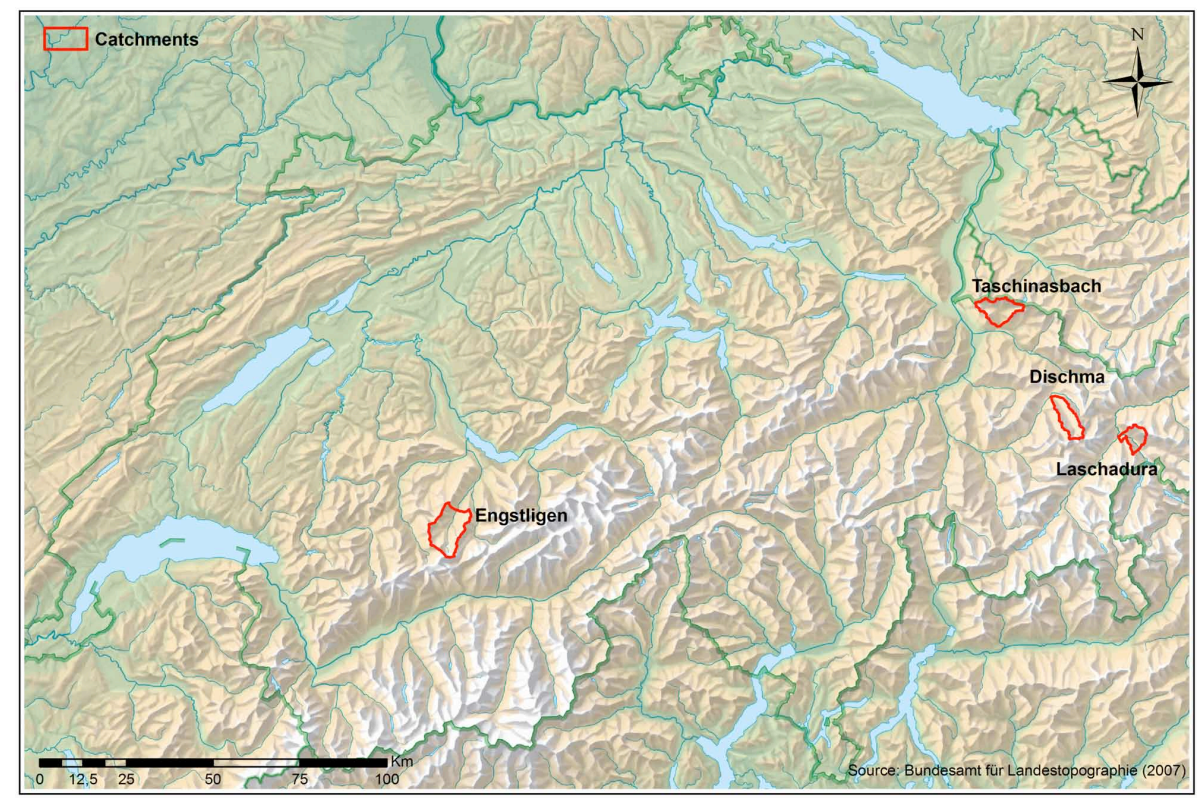

Fig. 1. Location of the four catchments in the Swiss Alps.

north-facing and south-facing slopes. The geographical location of these catchments is illustrated in Fig. 1. Three of the watersheds are located in the Eastern Alps close to the boarder to Austria and Italy: the north-facing one is the Taschinasbach, the south-facing one the Laschadura, and the one in between the Dischma catchment. The Engstligen catchment is located in the Western Alps or more precisely in the Bernese Alps. In all four catchments, snow samples were taken from a north-facing and a south-facing slope, with altitude differences between the sample points of $100 \mathrm{~m}$ covering a total altitude difference of approximately $1000 \mathrm{~m}$ (Fig. 2). Every sample location is presented in Fig. 2 with its associated elevation and aspect, highlighting the total altitude difference between 1200 and $3000 \mathrm{~m}$ and the focus on southern and northern aspects with a natural variability of the locations within the slopes. Additionally, GPS coordinates, slope inclination, aspect, and snow depth were measured at each sampling point. The first samples in the four catchments were taken at the end of the accumulation period in April 2010 and are named ACC samples; the second samples were taken in May 2010, approximately 30 days later, and are named MELT samples. In the Engstligen catchment, samples from a total of three ascents of the northern slopes were taken beginning of April, end of April and end of May, respectively. All sampling points were in the open and not influenced directly by vegetation cover. In total, 31 samples were collected in the Dischma catchment, 39 in the Engstligen, 23 in the Laschadura, and 34 in the Taschinasbach. The average distance between sampling points in one slope was $150 \mathrm{~m}$.

All samples were collected with an aluminum probe, which consists of three $1 \mathrm{~m}$ long pipes with a diameter of

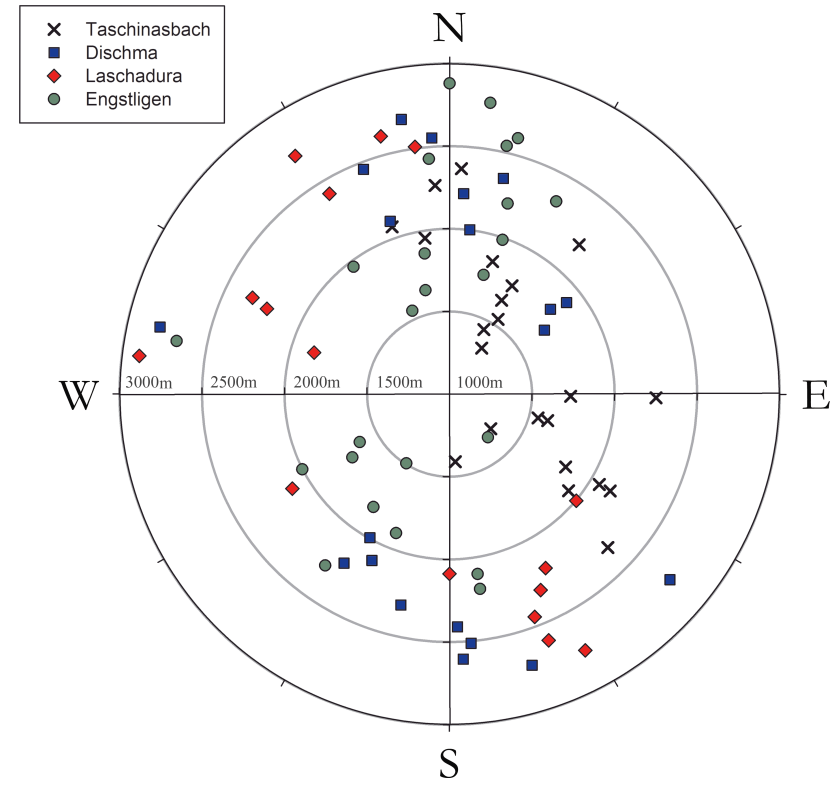

Fig. 2. Elevation and aspect of every sampled point of each catchment.

$6 \mathrm{~cm}$ that can be plugged together and secured by a screw. For all of the samples, the maximum length of the aluminum probe of $3 \mathrm{~m}$ was exceeded only at one point, where it had to be inserted an additional $20 \mathrm{~cm}$. To record the mean isotopic content of the entire snowpack, the aluminum probe was pushed to the ground at each point, which was checked by looking for soil or vegetation pieces at the bottom of the probe. The samples were collected according to the 
principles for collecting snow samples as described in Clark and Fritz (1997). The sampled snow was packed into airtight plastic bags and poured into bottles after it had melted. Thereby the snow was not melted actively; instead it could rather thaw slowly during transport and storage at room temperature. This process took, depending on the size and density of the snow sample, 5 to $15 \mathrm{~h}$. Since the melting process took place in a hermetically sealed plastic bag, an isotopic change of the samples was excluded.

Isotope analyses were conducted at the laboratory of the Chair of Hydrology, Freiburg University, Germany. For this purpose a Wavelength-Scanned Cavity Ring Down Spectrometer from Picarro was used. All isotope concentrations are expressed as $\delta$ values in per mil notation (\%o) relative to the Vienna standard mean ocean water (VSMOW). The standard error of the isotope analyser is $<0.2 \%$ for $\delta^{18} \mathrm{O}$ and $<1 \%$ for $\delta^{2} \mathrm{H}$. Hence one can infer that the relative standard error for $\delta^{18} \mathrm{O}$ is approximately twice that of $\delta^{2} \mathrm{H}$, assuming a relation based on the meteoric water line.

\subsection{Statistical analysis}

Stepwise multiple regression (MLR) analysis was carried out for every catchment and also for all samples taken. At first, $\delta^{18} \mathrm{O}$ and $\delta^{2} \mathrm{H}$ were chosen separately as response variables; however, it turned out that the same explanatory variables were selected. Therefore, the MLR was only applied to predict the observed variability of deuterium since the relative standard error of $\delta^{2} \mathrm{H}$ measurements is smaller than for $\delta^{18} \mathrm{O}$ and the behaviour of both isotopes in the hydrological cycle is nearly the same as long as evaporation is not a dominating process.

To determine the most meaningful MLR, all variables were first checked for multi-collinearity based on the variance inflation factor (VIF), the value of which should not exceed 10 (Helsel and Hirsch, 2002). None of the used variables exceeded a value of 5 . In order to obtain the most significant MLR equation, the selection of variables for each model was conducted by stepwise backward elimination according to the adjusted $R^{2}$ (Stahel, 2007). This procedure was performed with the statistical software "R" (http://www. r-project.org/index.html), like all other statistical analyses in this study. To select statistically relevant predictor variables, an automatically implied stepwise backward elimination according to the Akaike information criterion (AIC) was performed. After having chosen the most significant variables, every computed equation was checked for normal distribution, Cook's distance, outliers with leverage, and homoscedasticity. In addition, the $Z$ scores were calculated for the predictor and response variables of the final model to compare the relative influence of the predictor variables and explain the variability of the response variable.

The mean isotopic content of the entire snowpack for each given point in time is influenced by many factors. Since the isotopic content of individual precipitation events was not available, an attempt was made to specify the input by the altitude effect; thus the altitude of each sampling point was included as a predictor variable. During deposition of solid precipitation as snow, wind drift plays a major role. To describe this factor, the snow depth measured at the point was used as a further variable. Snow depth is not only influenced by wind drift, but also includes ablation processes. Since this parameter turned out not to be significant for the isotopic content of the sample points, a linear regression between altitude and snow depth was performed for each catchment and sampling date and the deviation of every point from the regression line was calculated. This deviation $\left(\Delta_{\text {snow }}\right)$ was used as the second predictor variable. After snow is deposited, the fractionation processes affecting the isotopic content of snow cover is mainly controlled by evaporation, percolation, and diffusion. These factors depend primarily on exposure. This factor may partly be described by snow depth, as at locations with high solar radiation, snow depth definitely will be less. Other factors that can exhibit the influence of solar radiation are slope, aspect, and vertical convexity $\left(C_{\text {vert }}\right)$. These three predictor variables were computed from a $25 \mathrm{~m}$ digital elevation model (DEM). Aspect was transformed with the cosine function and is therefore dimensionless, resulting in a value of -1 for north- and 1 for south-facing points. Values for the vertical convexity are given in $1 / 100$ of the $z$ unit $(\mathrm{m})$, while positive values indicate concavity and negative values convexity. To express enrichment of heavy isotopes during the ablation period, the day of the year (DOY) of sampling was included as well. Finally, longitude and latitude were derived from the GPS measurements.

\section{Results}

\subsection{Altitude influences on the variation of stable isotopes in snow}

An overview of the isotope sampling for the different catchments and time periods (accumulation and melt) is shown in the ${ }^{2} \mathrm{H}^{18} \mathrm{O}$ plot in Fig. 3. The upper graph shows the snow isotope samples of the four different catchments, including their local meteoric waterline (LMWL) for the accumulation period. Most samples lie very close to the global meteoric water line (GMWL) except some samples from the Dischma catchment. Samples taken during the melt period (lower graph) show a very similar pattern, with a slightly higher variability around the GMWL. However, strong kinetic fractionation affects are not visible in the samples.

An altitude effect throughout the entire snowpack is often superimposed by relocation of snow through wind drift and avalanches and also through an enrichment of heavy isotopes in upper layers of the snowpack that mostly depends on exposure to the sun. In the present work a significant $(p<0.1)$ altitude effect was determined for two of 15 sampling days (Fig. 4). These were the first two ascents 
Table 1. Correlation coefficients $\left(R^{2}\right)$ for different predictor variables and the response variable $\delta^{2} \mathrm{H}$.

\begin{tabular}{lccccc}
\hline $\begin{array}{l}\text { Predictor } \\
\text { variables }\end{array}$ & Engstligen & Taschinasbach & Dischma & Laschadura & All samples \\
\hline Altitude & 0.07 & 0.01 & 0.00 & $\mathbf{0 . 1 5}$ & 0.00 \\
$\Delta_{\text {snow }}$ & $\mathbf{0 . 1 8}$ & $\mathbf{0 . 1 4}$ & $\mathbf{0 . 1 5}$ & 0.00 & 0.04 \\
Slope & $\mathbf{0 . 1 0}$ & 0.05 & 0.01 & 0.02 & 0.00 \\
Aspect & $\mathbf{0 . 1 0}$ & 0.06 & 0.03 & $\mathbf{0 . 1 0}$ & 0.05 \\
$C_{\text {vert }}$ & $\mathbf{0 . 2 2}$ & 0.00 & 0.02 & 0.01 & 0.02 \\
DOY & $\mathbf{0 . 4 2}$ & $\mathbf{0 . 5 6}$ & $\mathbf{0 . 3 5}$ & $\mathbf{0 . 3 8}$ & $\mathbf{0 . 1 7}$ \\
Latitude & - & - & - & - & 0.01 \\
Longitude & - & - & - & - & $\mathbf{0 . 1 4}$ \\
\hline
\end{tabular}

Bold values are statistically significant correlations $(p<0.1)$.
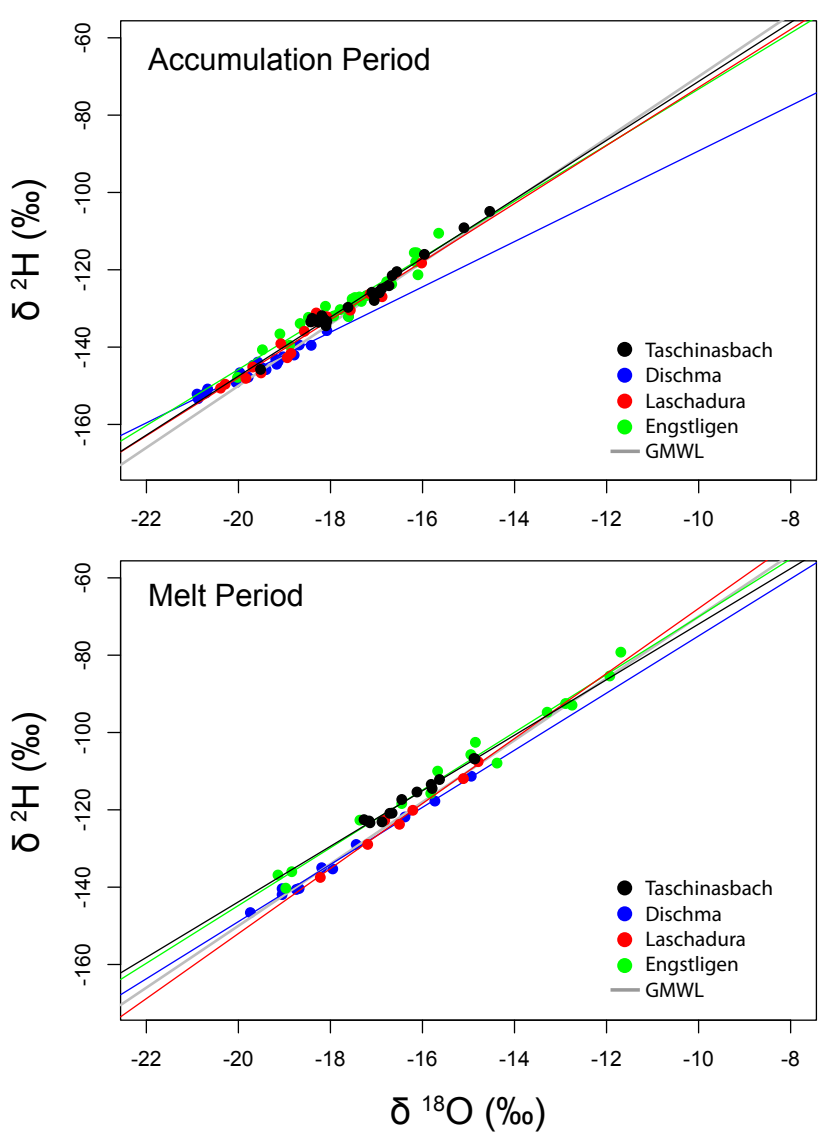

Fig. 3. ${ }^{2} \mathrm{H}-{ }^{18} \mathrm{O}$ plot of the four different catchments, including their local meteoric waterline (LMWL) for the accumulation (top panel) and melt (bottom panel) periods.

in the north-facing slopes of the Taschinasbach and Dischma catchments, with gradients of $\delta^{2} \mathrm{H}-2.6 \% / 100 \mathrm{~m}$ and $-0.7 \%$ o $100 \mathrm{~m}$ for $\delta^{2} \mathrm{H}$. The second ascents gradients were about -1.6 and $-1.4 \%$ o $/ 100 \mathrm{~m}$, respectively, but with a lower $R^{2}$ and a $p$ value larger than 0.1

A depletion of heavy isotopes with altitude could be observed in the first ascent samples of the north-facing slope of the Engstligen catchment with a gradient of $-0.7 \%$ o $100 \mathrm{~m}$ $\left(R^{2}=0.2\right)$, a gradient of $-0.9 \%$ o $/ 100 \mathrm{~m}\left(R^{2}=0.3\right)$ in the first ascent samples of the south-facing slope of the Dischma catchment, and gradients of -1.6 and $-6.2 \% \mathrm{o} / 100 \mathrm{~m}$ in the second ascent samples of the south-facing slopes of the Taschinasbach and Dischma catchments, respectively. The last two gradients are derived from five and three samples, respectively. For all other sampling dates and locations a positive gradient was observed, which ranged from 0.2 to $3.1 \%$ o $/ 100 \mathrm{~m}$. Especially in the Laschadura catchment all gradients represent a slight enrichment of heavy isotopes with altitude. Since only a few north-slope, first ascent gradients had a significant depletion gradient with altitude, whereas others had an enrichment gradient, altitude does not seem to significantly influence snow isotope composition.

When analysing the differences between first and second ascents, a distinct enrichment of heavy isotopes was observed. This enrichment ranged at individual sample points from 3 to $35 \% \circ \delta^{2} \mathrm{H}$ and in average for the catchments between 10 and $20 \%$ o $\delta^{2} \mathrm{H}$. Only in the Engstligen catchment did some sample points show a depletion of heavy isotopes from the first to the second sampling date. Since snow was disappearing relatively fast on the south-facing slopes, only a few points could be compared and moreover the samples of the second ascents were partly taken from a new snow cover rather than from the seasonal snow.

\subsection{Other influences on the variation of stable isotopes in snow}

For a first screening of the predictor variables, the correlation coefficient in each catchment between the predictors and the response variable $\delta^{2} \mathrm{H}$ was calculated and is shown in Table 1 . As already shown, altitude has only a limited explanatory power on $\delta^{2} \mathrm{H}$. Significant correlations $(p<0.1)$ were found for the Laschadura catchment in which an inverse altitudinal gradient was detected. In the other three catchments the deviation of snow depth $\Delta_{\text {snow }}$ is significantly correlated. The most significant variable in all catchments is the day of the year that explains the enrichment of heavy isotopes over 


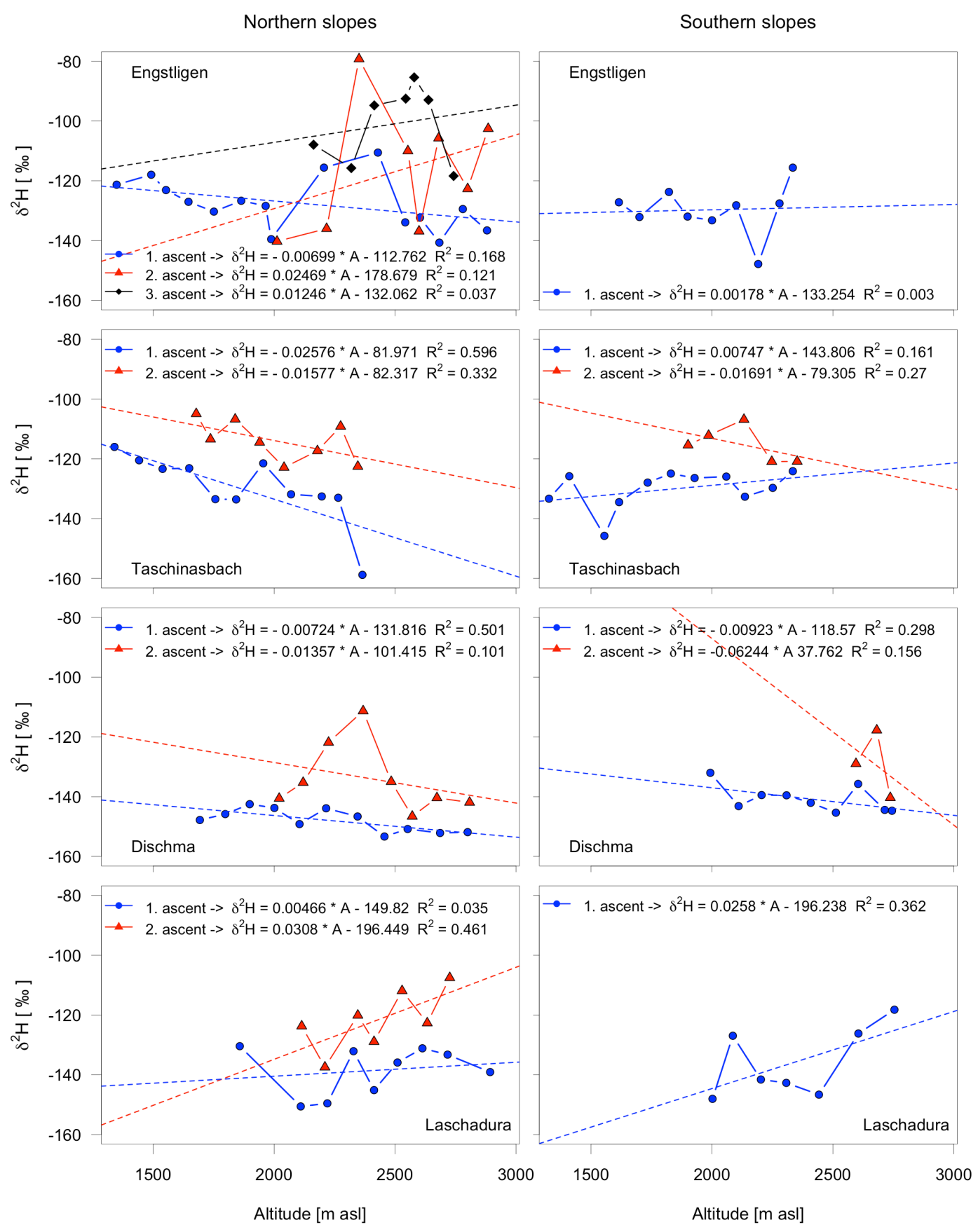

Fig. 4. Mean isotopic content of $\delta^{2} \mathrm{H}$ in snow cover at every sample point and associated altitudinal gradient for every sampling time (ascent).

the ablation period. Except for the Engstligen catchment, the variables slope, aspect and vertical convexity have only a small effect on the variation of $\delta^{2} \mathrm{H}$.

The stepwise multiple regression analysis with backward elimination supports the results of the individual linear regression analyses, and altitude, $\Delta_{\text {snow }}$, and DOY show a significant influence on $\delta^{2} \mathrm{H}$ (Table 2). At the Engstligen catchment aspect and vertical convexity $\left(C_{\text {vert }}\right)$ were additional predictor variables in the model and at the Laschadura catchment slope and $C_{\text {vert }}$ were selected as additional predictors. The adjusted $R^{2}$ for the MLR and the level of significance is also illustrated in Table 2.

To demonstrate the influence of one predictor variable on the response variable in dependence of the other variables in the model, a partial residual plot with every selected variable of the MLR is presented in Fig. 5. Apparently the significance of the variable altitude is more visible in the MLR than in the linear regression in Table 1, especially for 

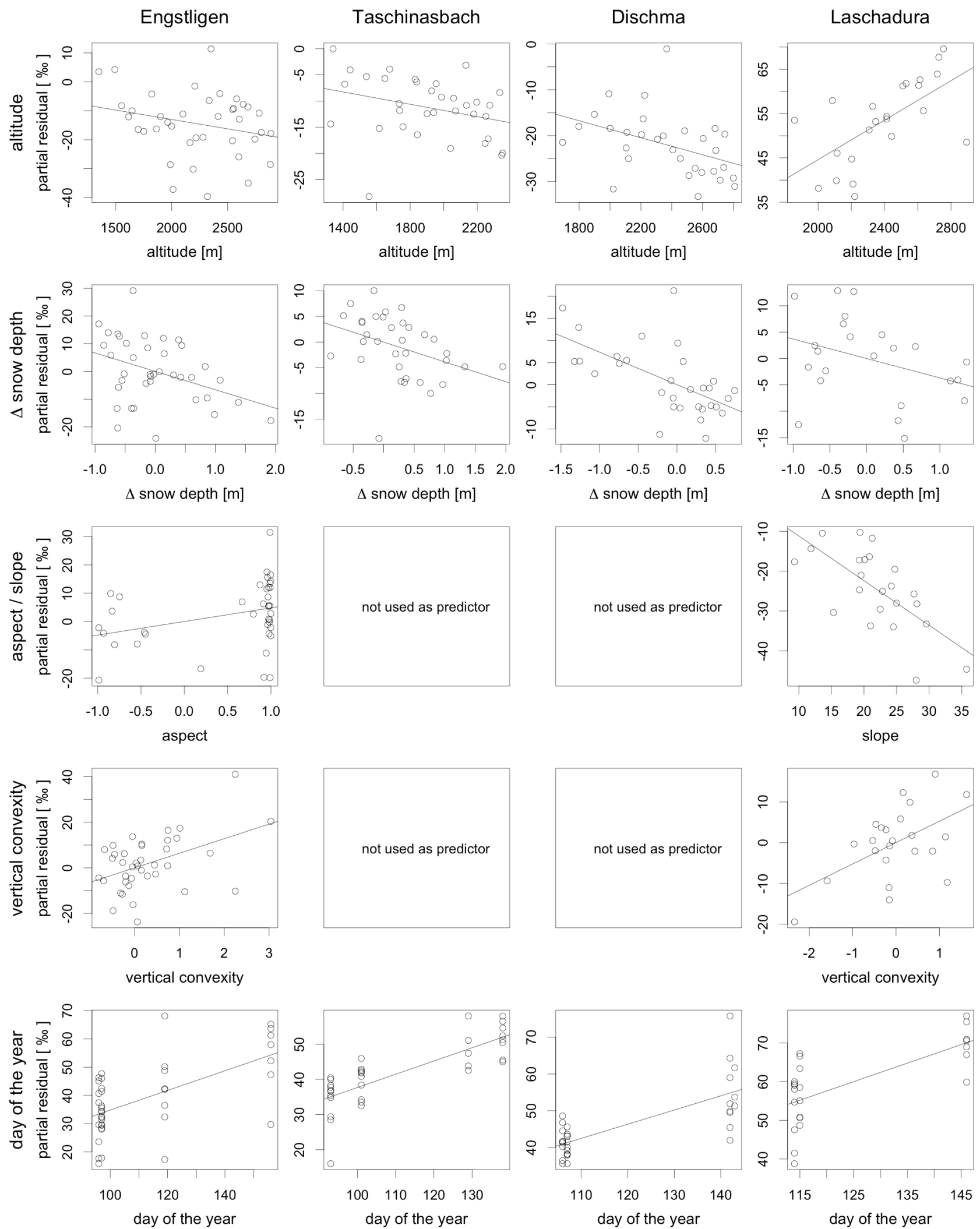

Fig. 5. Partial residuals of each predictor for the four watersheds selected by the stepwise MLR. 
Table 2. Adjusted $R^{2}$ for computed regression equations, level of significance ( $p$ value) and values of $\beta$-coefficients (ns $=$ predictor variable not selected, na $=$ not applicable).

\begin{tabular}{llllllll}
\hline Variables & Engstligen & Taschinasbach & Dischma & Laschadura & $\begin{array}{l}\text { All } \\
\text { accu }\end{array}$ & $\begin{array}{l}\text { All } \\
\text { melt }\end{array}$ & $\begin{array}{l}\text { All } \\
\text { samples }\end{array}$ \\
\hline Altitude & -0.0065 & -0.0059 & -0.0093 & 0.0223 & ns & ns & -0.0026 \\
$\Delta_{\text {snow }}$ & -6.66 & -3.86 & -7.34 & -7.34 & ns & -11.8 & -5.63 \\
Slope & ns & ns & ns & -1.12 & ns & ns & ns \\
Aspect & 4.8 & ns & ns & ns & ns & 6.9 & 2.25 \\
$C_{\text {vert }}$ & 6.39 & $n s$ & $n s$ & 5.24 & ns & ns & 1.11 \\
DOY & 0.348 & 0.377 & 0.386 & 0.48 & na & na & 0.40 \\
Latitude & na & na & na & na & 32.7 & 26.8 & 38.5 \\
Longitude & na & na & na & na & -8.23 & -8.7 & -11.4 \\
Intercept & -149.1 & -152.9 & -165.5 & -220.9 & -1589 & -1295 & -1863 \\
$R_{\mathrm{a}}^{2}$ & 0.5 & 0.61 & 0.54 & 0.51 & 0.32 & 0.42 & 0.55 \\
$p$ & $2.6 \times 10^{-5}$ & $6.4 \times 10^{-7}$ & $2.0 \times 10^{-5}$ & $3.1 \times 10^{-3}$ & $1.2 \times 10^{-7}$ & $2.1 \times 10^{-5}$ & $2.2 \times 10^{-16}$ \\
\hline
\end{tabular}

Table 3. Adjusted $R^{2}$ for computed regression equations, level of significance ( $p$ value) and values of $\beta$-coefficients for the MLR model of each catchment separated into accumulation and melt period $(\mathrm{ns}=$ predictor variable not selected, na $=$ not applicable).

\begin{tabular}{|c|c|c|c|c|c|c|c|c|}
\hline \multirow[t]{2}{*}{ Variables } & \multicolumn{2}{|c|}{ Engstligen } & \multicolumn{2}{|c|}{ Taschinasbach } & \multicolumn{2}{|c|}{ Dischma } & \multicolumn{2}{|c|}{ Laschadura } \\
\hline & acc & melt & acc & melt & acc & melt & acc & melt \\
\hline Altitude & ns & ns & -0.0118 & ns & -0.0074 & ns & 0.016 & 0.036 \\
\hline$\Delta_{\text {snow }}$ & ns & -13.6 & -7.83 & ns & $\mathrm{ns}$ & -8.2 & ns & -9.23 \\
\hline Slope & -0.699 & 0.638 & 0.061 & ns & ns & $\mathrm{ns}$ & -0.924 & -0.95 \\
\hline Aspect & 4.08 & ns & 4.21 & ns & 4.66 & ns & ns & 12.95 \\
\hline$C_{\text {vert }}$ & $\mathrm{ns}$ & ns & 5.12 & ns & $\mathrm{ns}$ & ns & 6.46 & ns \\
\hline Intercept & -115.2 & -126.9 & -118.7 & -116.9 & -127.5 & -133.5 & -156.3 & 199.2 \\
\hline$R_{\mathrm{a}}^{2}$ & 0.20 & 0.50 & 0.274 & na & 0.58 & 0.16 & 0.11 & 0.855 \\
\hline$p$ & 0.038 & 0.006 & 0.077 & na & 0.0002 & 0.12 & 0.24 & 0.094 \\
\hline
\end{tabular}

the Taschinasbach and Dischma catchments. The Dischma catchment shows the highest altitude gradient of all catchments. Furthermore, the inverse altitudinal gradient for the Laschadura catchment can be seen. For the Taschinasbach catchment the variable $\Delta_{\text {snow }}$ has a smaller effect in contrast to the other three catchments. A distinct influence by DOY is demonstrated in samples for all catchments. The variable vertical convexity represents a significant effect only in the Engstligen and Laschadura catchments and the other two variables (aspect and slope) play a distinctive role in only the Laschadura catchment.

Since DOY strongly influenced the MLR, but the samples were more or less only taken at two dates, one during the accumulation and one during the melt period, the assumption of a linear relation could be questioned. Therefore, the samples for each catchment were divided into samples taken during the accumulation period and during the melt period, and the MLR was applied individually. The results of the stepwise MLR are presented in Table 3. For most catchments, the predictors differ between the accumulation and the melt period. During the accumulation period, altitude, slope, aspect and vertical convexity explain most of the variability.
During the melt period, the variables $\Delta_{\text {snow }}$, slope and aspect are most frequently selected as predictor variables. The adjusted $R^{2}$ varies strongly between the catchments and periods with no obvious trend that the accumulation or melt period can be better modelled; however, no predictors show any significance to predict the observed differences of the melt period in the Taschinasbach catchment. There is also no clear indication that one predictor has a stronger influence to explain the observed variability in $\delta^{2} \mathrm{H}$.

For the MLR, including data from all catchments and all sampling dates, the predictors latitude and longitude were additionally included and mainly longitude turned out to be significant (Fig. 6 and Table 2). $\Delta_{\text {snow }}$ and DOY were the most significantly variables. The variables altitude, aspect, vertical convexity and latitude had a minor influence. The regression equitation for all samples had an adjusted $R^{2}$ of 0.55 with a level of significance $p=2.2 \times 10^{-16}$. When the data were split into accumulation and melt period, only latitude and longitude showed a significant influence on $\delta^{2} \mathrm{H}$ with a relative low adjusted $R^{2}$ of 0.32 during the accumulation period. During the melt period, $\Delta_{\text {snow }}$ was the most significant variable of influence, with a minor influence of aspect, latitude 

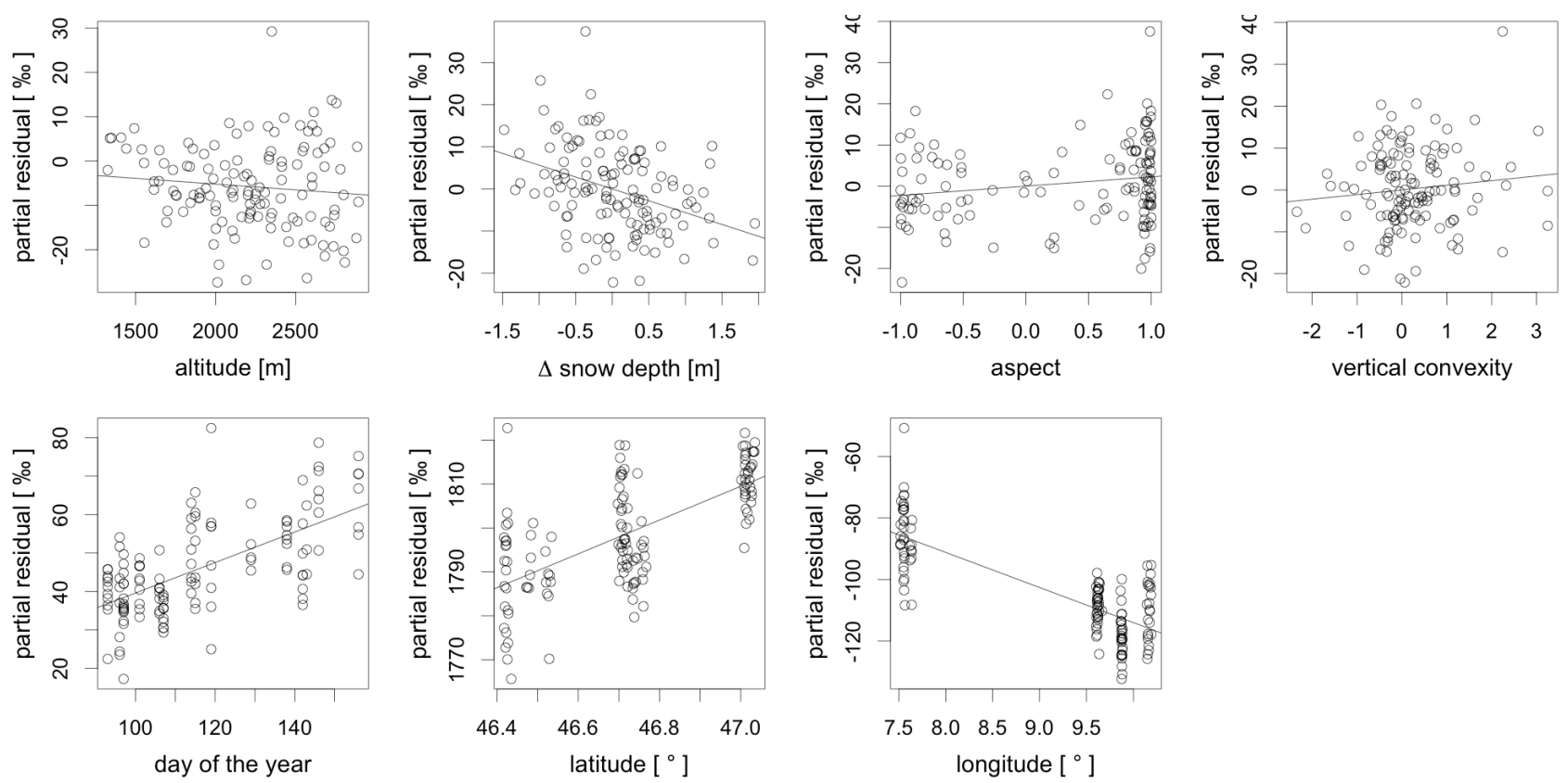

Fig. 6. Partial residuals of each predictor in the regression equitation for all samples.

and longitude during this period. The adjusted $R^{2}$ was again lower than for the MLR of the individual catchments or the whole dataset.

\section{Discussion}

The altitude effect of $\delta^{2} \mathrm{H}$ of fresh snow in the Alps was examined by Moser and Stichler (1970), who found an elevation gradient of $-3 \% / 100 \mathrm{~m}$ and deviations between -2 and $-10 \% / 100 \mathrm{~m}$. It has also been established that every single snowfall has its own isotopic signature and accumulates stratigraphically, providing a weighted average signature of the entire snowpack with slight changes due to melting processes (Raben and Theakstone, 1994). In the final accumulation and melting season, these processes, caused by solar radiation and temperature variations, can substantially alter the isotopic content of snow and therefore lead to differing and even inverse altitudinal gradients on a total snowpack scale (Moser and Stichler, 1974). In the current study a significant altitudinal gradient for entire snow cover was only observed in the first sampling dates of some north-facing slopes, ranging between -2.6 and $-0.7 \% / 100 \mathrm{~m}$. On the second date of sampling, the gradients were less pronounced. In addition, the altitudinal gradients at the south-facing slopes ranged from -6.2 to $2.6 \%$ o $100 \mathrm{~m} \delta^{2} \mathrm{H}$ with a wide variability of the individual samples. These results confirm in particular the influence of melting processes on the mean isotopic content of snow cover for the south-facing slopes. For further interpretation of the altitudinal gradients, only the results from the north-facing slopes will be discussed. Recent studies (e.g. Moran et al., 2007) pointed out that an altitudinal effect in fresh snow strongly depends on the type of weather system and that Raleigh distillation can lead to inverse altitudinal gradients in leeward slopes. This is maybe the case in the Laschadura catchment, which is located east of the upper Inn River valley (Upper Engadin) and where all altitudinal gradients show an enrichment of heavy isotopes with altitude.

The effect of higher condensation levels, as for example discussed by Siegenthaler and Oeschger (1980), inducing isotopic depleted precipitation can be seen in the Dischma catchment. The snow cover is on average isotopically more depleted than in the other catchments and furthermore the altitudinal gradient is less distinctive than in the nearby Taschinasbach catchment, which is located at the same longitude but $50 \mathrm{~km}$ further north, at the edge of the Alps. In the Engstligen catchment, which is located in the Bernese Alps, no altitudinal gradient was significant. The north-facing slope of this catchment is a steep avalanche-prone slope popular for ski touring, factors that likely lead to transport of snow and disturb the altitudinal gradient. The above finding was supported by a third sampling date for which samples also show a widespread isotopic signature.

The large deviations of $\delta^{2} \mathrm{H}$ values from the expected decrease with elevation at the end of the accumulation period suggest that there is significant enrichment in some locations. Barring melt at the higher elevations, a likely explanation for this enrichment is water vapour losses from the snowpack. Snowpacks exposed to high solar radiation during the accumulation season exhibit kinetic fractionation of water isotopes (Gustafson et al., 2010; Biederman et al., 
2012), although equilibrium fraction also could be expected to increase $\delta^{2} \mathrm{H}$ values relative to fresh snow (Earman et al., 2006). Furthermore, Groot Zwaftink et al. (2013) have suggested that sublimation of blowing snow is minimal in the region, with most vapour fluxes occurring from a stable snow surface. Thus, one would expect that locations that exhibit more enriched values are subject to greater sublimation fluxes and thus $\Delta_{\text {snow }}$ (deviation of snow depth from the expected value) should be larger and negative while those that are more depleted should represent protected environments, have positive delta snow values, and have minimal changes in isotopic content that follow the local meteoric water line. The general enrichment of $\delta^{2} \mathrm{H}$ with elevation on south facing slopes before melt is consistent with higher vapour fluxes in higher elevations that are less likely to be topographically shaded. These observations further highlight the importance of radiative forcing on snowpack mass and energy balance. The data in Figs. 4-6 on $\delta^{2} \mathrm{H}$ and $\Delta_{\text {snow }}$ relationships with aspect and elevation before melt seem consistent with spatial distribution in vapour exchange with the atmosphere.

To conclude, a significant altitudinal gradient exists only in some north-facing slopes during the end of the accumulation period. For all south-facing slopes and for northfacing slopes during the melting season, the potential altitudinal gradients are disturbed by melting processes. These processes influence the isotopic content of the entire snow cover in dependence of the exposure to the sun and can be seen in the magnitude of enrichment on heavy isotopes between the first and second ascent samples. This result is similar to findings of Gustafson et al. (2010), who detected significant spatial variations of Deuterium and ${ }^{18} \mathrm{O}$ in snowpack but not in precipitation.

The goal of the stepwise multiple regression was to discover correlations and interactions between isotopic signature of snow cover at a point scale in dependence of altitude and other predictors. In general, the deviation of snow depth $\Delta_{\text {snow }}$ explains more of the observed variability than altitude. This variable represents the measured snow depth relative to the expected snow depth based on altitude and explains, for the north-facing slopes, transport of snow through wind drift and avalanches and, for the south-facing slopes, influences of melting processes resulting in decreasing snow depth. The most significant variable is DOY, which explains the enrichment of heavy isotopes in snow cover through melting processes during the ablation period. This enrichment between the first and the second sampling dates varied from 3 to $35 \%$ of $\delta^{2} \mathrm{H}$ at the individual points and from 10 to $20 \%$ of $\delta^{2} \mathrm{H}$ at catchment scale.

The results from the MLR show that only between 50 and $61 \%$ of the observed variation of stable isotopes of water in the entire snowpack can be explained by the selected predictors. The influence of some predictors are relatively stable among the catchments, in particular DOY and $\Delta_{\text {snow }}$. At the Laschadura and Engstligen catchments the results are improved slightly by the additional predictors' vertical convexity, slope and aspect. The MLR applied to all catchments shows that longitude is the most significant variable, followed by DOY, latitude and $\Delta_{\text {snow }}$. The variables altitude, slope and vertical convexity have a lesser effect. The strong influence of longitude can be attributed to the continental effect, which defines the depletion of heavy isotopes in precipitation during the trajectories of air masses among the continents (Dansgaard, 1964). Including latitude in regression equitation was an attempt to specify the spatial contribution of the isotopic content at the catchments additional to the mentioned continental effect. Table 1 shows that latitude has only a limited influence when used as a single predictor, but in Fig. 5 it is demonstrated that it has a more pronounced influence when used in the MLR. Samples for this research were collected over a period of 63 days. Despite the wide spatial contribution of the catchments, the enrichment of heavy isotopes during ablation, presented by the variable DOY, is the most significant predictor in the correlation and the second most important predictor in the multiple regression. In addition, $\Delta_{\text {snow }}$ has a distinctive influence on the isotopic content of snow cover at individual catchments as well as for all catchments.

In summary, the predictor variables altitude, aspect, slope and vertical convexity can hardly explain the variation of stable isotopes in alpine snow cover. This is due to the high variability of the isotopic composition of the precipitation during the winter months, which are all preserved in the snow cover and influenced by enrichment of heavy isotopes due to melting processes. Instead, the snow depth relative to the expected snow depth based on elevation, which can be measured easily, and the day of the year have significant effects in predicting stable isotopes of water at the catchment scale.

For all studies that require information about the isotopic content of the snowpack in a catchment or other region, detailed information on the spatial and temporal variability of the isotopic content of snow is required. The input of water input in snow dominated watershed for residence time analysis, end member mixing analysis or the detection of source water contribution requires detailed knowledge about the effects modifying the isotopic content of the snow cover. Because this information is not yet available, this study provides a first attempt using a large dataset to derive the variables in addition to altitude (which is usually assumed to mainly alter the isotopic content of the snowpack) that influence the spatial and temporal alteration in the snowpack and hence finally in the meltwater. Using the results and information of this study should support the measurement of mean isotopic content of the snowpack at two points in a catchment during time as well as predicting the spatial distribution of the isotopic content in the snow cover based on snow depth observations or modelling, since $\Delta_{\text {snow }}$, the deviation of snow depth from the expected value, is one of the most significant variable within a watershed to explain the spatial variability. Using the information over time at the two sampling points, the enrichment specific for this season can be calculated by 
the day of the year and hence the isotopic content of the meltwater as suggested in Laudon et al. (2002).

\section{Conclusions}

To better understand the different factors such as altitude, aspect, slope and other factors influencing the stable isotope composition of the entire snowpack, we sampled stable water isotopes in the snowpack at the end of the accumulation and during the ablation period at eight different slopes in four catchments in Switzerland, covering an altitude difference of approximately $1000 \mathrm{~m}$ per slope. We could prove the hypothesis that additional factors like the deviation of snow depth from the expected value due to altitude and the day of the year influence the variation of stable water isotopes in snow in space and time. These variables may therefore serve as additional important predictors to altitude to predict the spatial and temporal variability of stable water isotopes in the entire snowpack. We could also demonstrate that the isotopic content varies along elevation gradients (presumably due to temperature effects on precipitation formation), by latitude (presumably due to distance from water source), by season (presumably due to differences in isotopic controls during accumulation and ablation season), and by aspect (presumably due to differential enrichment during ablation). When taken together, these relationships clearly demonstrate that spatial variability in potential snowmelt water isotopes before melt is high, and that the timing of meltwater isotopic input varies with catchment morphology. Given the importance of snow cover in montane catchments to downstream water resources for over 1 billion people worldwide, advances in placing variability in snow cover within catchment hydrological response is a critical area for research. We need more research to understand the isotopic development of the snowpack in time and space and its affect on the isotope content of meltwater during the ablation period to increase model performance of residence time models for alpine areas in order to better understand the accumulation processes and the sources of water in the snow cover of high mountains.

Acknowledgements. The authors thank Barbara Herbstritt for supporting the isotope analysis. This study was part of the master thesis of Nicolai Dietermann, who died in an accident in the mountains of Kyrgyzstan when sampling snow isotopes for his $\mathrm{PhD}$ and finishing this paper. I would like to thank all who supported me and his parents and friends during the difficult time after his death. Paul Brooks, Nils Ohlanders and an anonymous reviewer provided very valuable feedback and suggestions that improved the paper considerably.

Edited by: N. Romano

\section{References}

Aizen, V., Aizen, E., Melack, J., and Martma, T.: Isotopic measurements of precipitation on central Asian glaciers (Southeastern Tibet, northern Himalayas, central Tien Shan), J. Geophys. Res., 101, 9185-9198, 1996.

Ambach, W., Eisner, H., and Pessl, K.: Isotopic oxygen composition of firn, old snow and precipitation in alpine regions, $\mathrm{Z}$. Gletscherk. Glazialgeol., 8, 125-135, 1972.

Arnason, B., Buason, T., Martinec, J., and Theodôrsson, P.: Movement of water through a snowpack traced by deuterium and tritium, Role of Snow and Ice in Hydrology, (Proceedings of the Banff Symposium, Canada, September 1972), IAHS Publ., 107, 299-312, 1972.

Biederman, J. A., Brooks, P. D., Harpold, A. A., Gutmann, E., Gochis, D. J., Reed, D. E., and Pendall, E.: Multi-scale Observations of Snow Accumulation and Peak Snowpack Following Widespread, Insect-induced Lodgepole Pine Mortality, Ecohydrology, doi:10.1002/eco.1342, in press, 2012.

Clark, I. D. and Fritz, P.: Environmental isotopes in hydrogeology, CRC Press, New York, 1997.

Cooper, L. W.: Isotopic Fractionation in Snow Cover, in: Isotope Tracers in Catchment Hydrology, edited by: Kendall, C. and McDonnell, J. J., Elsevier, Amsterdam, 87-118, 1998.

Dansgaard, W.: Stable isotopes in precipitation, Tellus, 16, 436468, 1964.

Dincer, T., Payne, B. R., Florkowski, T., Martinec, J., and Tongiorgi, T.: Snowmelt runoff from measurements of tritium and oxygen18, Water Resour. Res., 6, 110-118, 1970.

Earman, S., Campbell, A. R., Phillips, F. M., and Newman, B. D.: Isotopic exchange between snow and atmospheric water vapor: Estimation of the snowmelt component of groundwater recharge in the southwestern United States, J. Geophys. Res., 111, D09302, doi:10.1029/2005JD006470, 2006.

Friedman, I. and Smith, G.: Deuterium content of snow cores from Sierra Nevada area, Science, 169, 467-470, 1970.

Gat, J. R.: Oxygen and hydrogen isotopes in the hydrologic cycle, Annu. Rev. Earth Planet. Sci., 24, 225-262, 1996.

Gonfiantini, R.: Discussion, Isotope Hydrology, IAEA, Vienna, p. $56,1970$.

Groot Zwaaftink, C. D., Mott, R., and Lehning, M.: Seasonal simulation of drifting snow sublimation in Alpine terrain, Water Resour. Res., 49, 1581-1590, 2013.

Gurney, S. D. and Lawrence, D. S. L.: Seasonal trends in the stable isotopic composition of snow and meltwater runoff in a subarctic catchment at Okstindan, Norway, Nord. Hydrol., 35, 119-137, 2004.

Gustafson, J. R., Brooks, P. D., Molotch, N. P., and Veatch, W. C.: Estimating snow sublimation using natural chemical and isotopic tracers across a gradient of solar radiation, Water Resour. Res., 46, W12511, doi:10.1029/2009WR009060, 2010.

Helsel, D. and Hirsch, R.: Statistical Methods in Water Resources, Techniques of Water-Resources Investigations of the United States Geological Survey, Hydrologic Analysis and Interpretation, United States Geological Survey and the US Department of Interior, 1-504, 2002.

Judy, C., Meiman, J. R., and Friedman, I.: Deuterium variations in an annual snowpack, Water Resour. Res., 6, 125-129, 1970. 
Königer, P., Hubbart, J. A., Link, T., and Marshall, J. D.: Isotopic variation of snow cover and streamflow in response to changes in canopy structure in a snow-dominated mountain catchment, Hydrol. Process., 22, 557-566, 2008.

Laudon, H., Hemond, H. F. , Krouse, R., and Bishop, K. H.: Oxygen 18 fractionation during snowmelt: Implications for spring flood hydrograph separation, Water Resour. Res., 38, 1258, doi:10.1029/2002WR001510, 2002.

Martinec, J., Moser, H., De Quervain, M. R., Rauert, W., and Stichler, W.: Assessment of processes in the snowpack by parallel deuterium, tritium and oxygen-18 sampling, Isotopes and Impurities in Snow and Ice (Proceedings of the Grenoble Symposium, Switzerland, September 1972), IAHS Publ., 118, 220-231, 1977.

Mast, M. A., Kendall, C., Campbell, D. H., Clow, D. W., and Back, J.: Determination of hydrologic pathways in an alpine-subalpine basin using isotopic and chemical tracers, Loch Vale Watershed, Colorado, USA, Biogeochemistry of Seasonally Snowcovered Catchments (Proceedings of a Boulder Symposium, USA, Juli 1995), IAHS Publ., 228, 263-270, 1995.

McDonnell, J. J.: Where does water go when it rains? Moving beyond the variable source area concept of rainfall-runoff response, Hydrol. Process., 17, 1869-1875, 2003.

Moran, T. A., Marshall, S. J., Evan, E. C., and Sinclair, K. E.: Altitudinal gradients of stable isotopes in lee-slope precipitation in the Canadian Rocky Mountains, Arct. Antarct. Alpine Res., 39, 455-467, 2007.

Moser, H. and Stichler, W.: Deuterium measurements on snow samples from the Alps, Isotope Hydrology, IAEA, Vienna, 43-57, 1970.

Moser, H. and Stichler, W.: Die Verwendung des Deuteriumund Sauerstoff-18-Gehalts bei hydrologischen Untersuchungen, Geol. Bavarica, 64, 7-35, 1971

Moser, H. and Stichler, W.: Deuterium and oxygen-18 contents as an index of the properties of snow covers, Snow Mechanics (Proceedings of the Grindelwald Symposium, Switzerland, April 1974), IAHS Publ., 114, 122-135, 1974.

Niewodniczanski, J., Grabczak, J., Baranski, L., and Rzepka, J.: The altitude effect on the isotopic composition of snow in high mountains, J. Glaciol., 95, 99-111, 1981.

Raben, P. and Theakstone, W. H.: Isotopic and ionic changes in a snow cover at different altitudes: observations at Austre Okstindbreen in 1991, Ann. Glaciol., 19, 85-91, 1994.
Renaud, A.: Etudes physiques et chimiques sur la glace de l'indlandsis du Groenland 1959, in: Section 3.1, edited by: Dansgaard, W., Merlivat, L., and Roth, E., Medd. Grnl., 177, 62-76, 1969.

Rodhe, A.: Spring flood meltwater or groundwater?, Nord. Hydrol., 12, 21-30, 1981.

Schelker, J., Burns, D. A., Weiler, M., and Laudon, H.: Hydrological mobilization of mercury and dissolved organic carbon in a snowdominated, forested watershed: Conceptualization and modeling, J. Geophys. Res., 116, G01002, doi:10.1029/2010JG001330, 2011.

Shanley, J. B., Kendall, C., Smith, T. E., Wolock, D. M., and McDonnell, J. J.: Controls on old and new water contributions to stream flow at some nested catchments in Vermont, USA, Hydrol. Process., 16, 589-609, 2002.

Siegenthaler, U. and Oeschger, H.: Correlation of ${ }^{18} \mathrm{O}$ in precipitation with temperature and altitude, Nature, 285, 314-317, 1980.

Sinclair, K. E. and Marshall, J. S.: Post-depositional modification of stable water isotopes in winter snowpacks in the Canadian Rocky Mountains, Ann. Glaciol., 1, 96-106, 2008.

Sokratov, S. A. and Golubev, V. N.: Snow isotopic content change by sublimation, J. Glaciol., 55, 823-828, 2009.

Stahel, W. A.: Statistische Datenanalyse: Eine Einführung für Naturwissenschaftler, 5. Aufl., Vieweg, Wiesbaden, 2007.

Stichler, W., Schotterer, U., Fröhlich, K., Ginot, P., Kull, C., Gäggeler, H., and Pouyaud, B.: Influence of sublimation on stable isotope records recovered from high-altitude glaciers in the tropical Andes, J. Geophys. Res., 19, 22613-22620, 2001.

Unnikrishna, P. V., McDonnell, J. J., and Kendall, C.: Isotope variations in a Sierra Nevada snowpack and their relation to meltwater, J. Hydrol., 1-4, 38-57, 2002.

Vitvar, T., Aggarwal, P. K., McDonnell, J. J.: A Review of Isotope Applications in Catchment Hydrology, in: Isotopes in the Water Cycle: Past, Present and Future of a Developing Science, edited by: Aggarwal, P. K., Gat, J. R., Froehlich, K. F. O., IAEA, Dordrecht, the Netherlands, 151-169, 2007.

Wels, C., Cornett, R. J., and Lazerte, B. D.: Hydrograph separation: a comparison of geochemical and isotopic tracers, J. Hydrol., 122, 253-274, 1991. 